\title{
HIGH-EFFICIENCY MATCHING NETWORK FOR RF-DRIVEN ION SOURCES *
}

\author{
J. Staples, T. Schenkel, LBNL, Berkeley, CA 94720, USA
}

\section{Abstract}

RF-driven ion sources used at LBNL connect a $2 \mathrm{MHz}$ transmitter to an antenna in the plasma generator through an impedance matching network. Previous networks are of low efficiency and require a high-power RF transmitter to excite the plasma. A new network topology provides significantly higher efficiency and matches very lowinductance antennas, with a geometrically preferred form factor. A dual-frequency network option allows a low-level 13.56 MHz transmitter to pre-excite the plasma, eliminating the need for other ignition devices such as a filament or laser, simplifying source construction. Experimental results will be presented.

\section{RF-DRIVEN ION SOURCES}

LBNL has long used low-frequency (2 MHz) excitation of the plasma in cusp-field negative and positive ion sources [1], such as the $\mathrm{H}^{-}$source for the Spallation Neutron Source Project [2]. An antenna, such as that shown in Fig. 1, is immersed in the plasma and excited by a lowfrequency r.f. generator at powers from a few watts to several tens of kilowatts. The antenna presents both a resistive and inductive load and is matched to the 50-ohm output of the r.f. source through an impedance matching network.

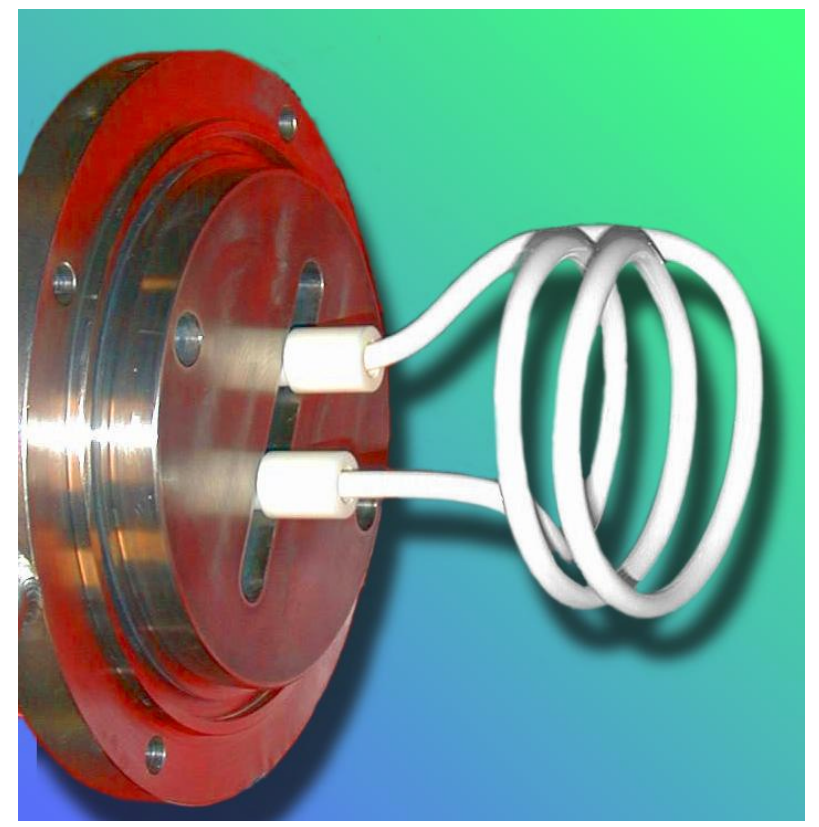

Figure 1: Antenna

${ }^{*}$ This research is sponsored by the Director, Office of Science, Office of Basic Energy Science, of the U.S. Department of Energy, Contract No. DE-AC03-76SF00098
Previously, an inductively-coupled network has used a ferrite-loaded transformer driving a series-resonant circuit in the secondary that includes the antenna, as shown in Fig. 2. The transformer is quite lossy and contributes to the inefficiency of the network, requiring an expensive power amplifier to make up for the losses in the network.

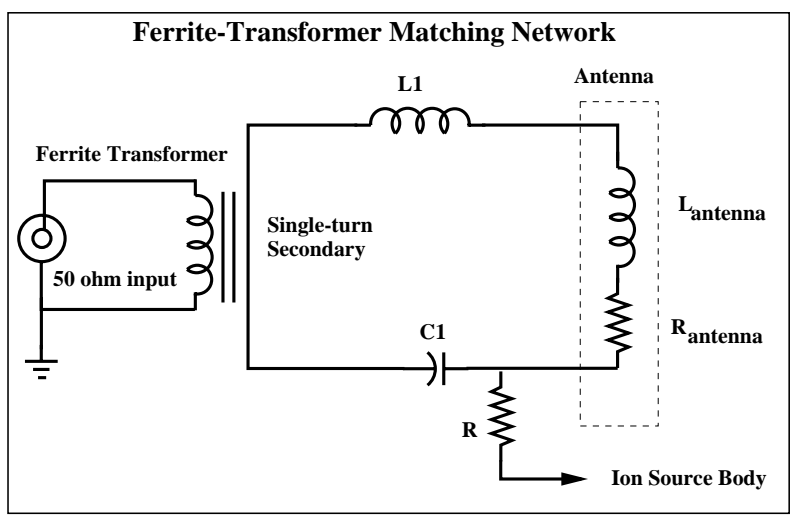

Figure 2: Ferrite Transformer Network

\section{NEW MATCHING NETWORK}

A more efficient capacitively-coupled network has been developed which overcomes many of the deficiencies of the inductive network, which, by eliminating the transformer, provides an infinitely adjustable match, instead of coarsely quantized by taps on the transformer primary, matching a wide variety of antennas, including very low impedance antennas, and opens the possibility of simultaneously exciting the plasma with more than one frequency [3], [4].

The new network uses a capacitance voltage divider instead of a ferrite-loaded transformer to match the 50-ohm generator impedance to the complex antenna impedance.

Fig. 3 shows the circuit topology of the capacitivelycoupled network. The transmitter connects to the 50-ohm input and feeds a capacitance voltage divider made up of capacitors $C_{1}$ and $C_{2}$, which feeds the antenna with equivalent inductance $L_{\text {antenna }}$ and series resistance $R_{\text {antenna }}$. The antenna is resonated by inductor $L_{1}$, which stabilizes the resonant frequency of the network. As the plasma ignites, the equivalent antenna inductance $L_{\text {antenna }}$ decreases significantly, and without the large series inductance $L_{1}$, the resonant frequency of the network would move out of the resonant bandwidth. This is especially true, as the losses in this network, compared to the ferritetransformer network, are low, leading to a high $\mathrm{Q}$ and therefore narrow bandwidth.

We have found that the plasma is more stable if the an- 


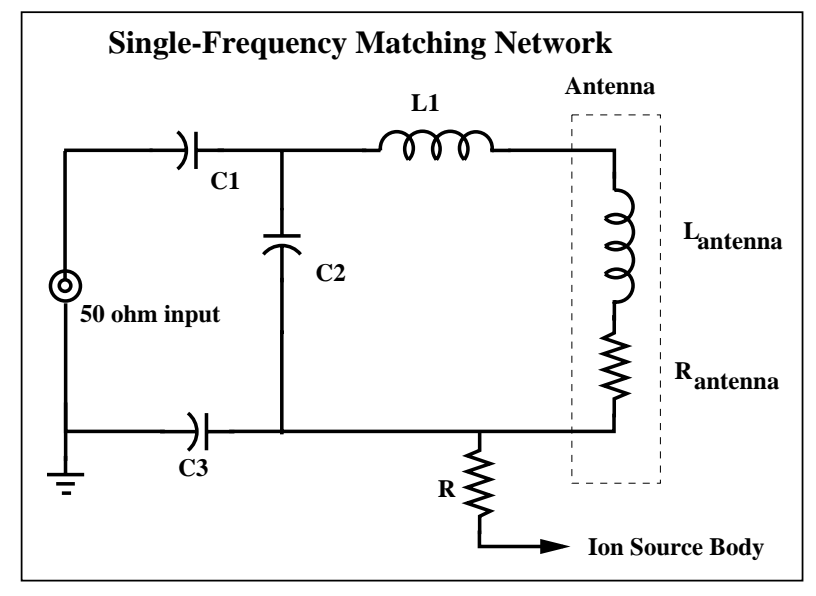

Figure 3: Single-Frequency Network

tenna is d.c.-isolated from the ion source body potential and connected to it through a large-value resistor $R$. This resistor typically has a value of several tens of kilo-ohms.

The transformer-coupled network provides this isolation naturally, and in the case of the new network, the d.c. isolation is provided by capacitor $C_{1}$, part of the capacitive voltage divider, and by a large capacitor $C_{3}$, which has a very low reactance at the operating frequency. Table 1 shows typical component values for the single-frequency $2 \mathrm{MHz}$ network.

\begin{tabular}{|c|l|}
\hline Component & Value \\
\hline$C_{1}$ & 220 picofarads \\
$C_{2}$ & 1760 picofarads \\
$L$ & 2.7 microhenries \\
\hline$C_{3}$ & 0.01 microfarads \\
\hline
\end{tabular}

Table 1: Single-Frequency Component Values

Typical values for the antenna inductance and resistance in the presence of a well-developed plasma are 0.5 microhenries $(6.3 \mathrm{j} \mathrm{ohms}$ at $2 \mathrm{MHz})$ and $0.6 \mathrm{ohms}$.

The value of $L_{1}$ is several times the antenna equivalent inductance, which stabilizes the network frequency when $L_{\text {antenna }}$ varies with plasma conditions, which is powerdependent. Typically 10 to $50 \mathrm{~kW}$ power is provided from the $2 \mathrm{MHz}$ transmitter which excites the antenna with several hundred rms r.f. amperes.

\section{DUAL-FREQUENCY NETWORK}

Ignition of the plasma in a pulsed ion source may be accomplished with several ways of providing the initial electrons with the characteristics shown in Table 2.

The new network is easily adaptable to dual-frequency operation, allowing continuous low-level r.f. power at a different frequency, $13.56 \mathrm{MHz}$ in this case, to be introduced to the plasma as a keep-alive excitation. The network can provide good isolation between the two r.f. sources, the primary one operating at $2 \mathrm{MHz}$.

\begin{tabular}{|l|l|}
\hline Method & Characteristics \\
\hline Brute force with power & $\begin{array}{l}\text { Delayed firing, high stand- } \\
\text { ing wave ratio before igni- } \\
\text { tion. }\end{array}$ \\
\hline Filament & $\begin{array}{l}\text { Short filament life, evapo- } \\
\text { rate coats antenna, reduc- } \\
\text { ing efficiency. }\end{array}$ \\
\hline Flashlamp & Weak effect \\
\hline Laser & $\begin{array}{l}\text { Expensive and requires } \\
\text { laser safety precautions }\end{array}$ \\
\hline Second r.f. excitation & $\begin{array}{l}\text { Effective, as described be- } \\
\text { low }\end{array}$ \\
\hline
\end{tabular}

Table 2: Plasma Ignition

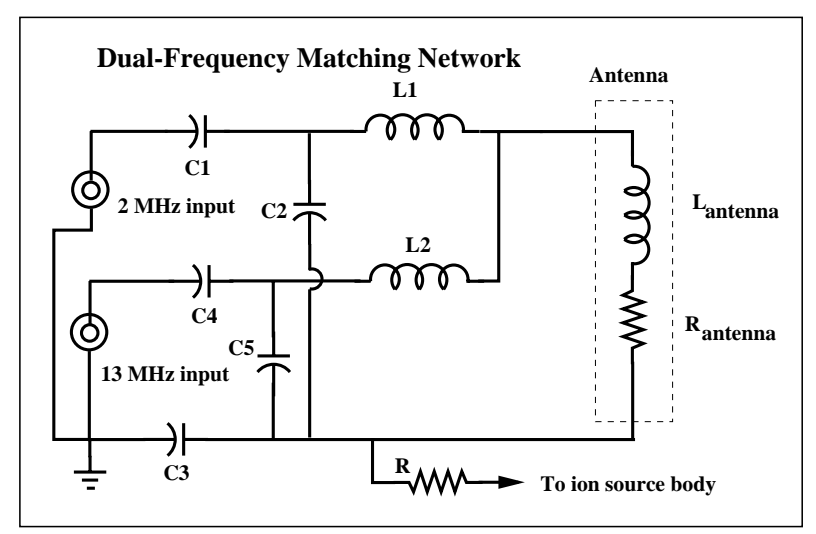

Figure 4: Dual Frequency Network

Fig. 4 shows the addition of a second channel to the network. Isolation is enhanced between the two input ports by using a high-C, low-L configuration in the low-frequency channel, and a low-C, high-L configuration in the highfrequency channel. The isolation with the circuit values given below are $-47 \mathrm{db}$ from the 2 to the $13.56 \mathrm{MHz}$ input port, protecting the small $13.56 \mathrm{MHz}$ transmitter from the large power of the $2 \mathrm{MHz}$ transmitter. The isolation in the other direction is lower, $-17 \mathrm{db}$, which is adequate.

\begin{tabular}{|c|l|}
\hline Component & Value \\
\hline$C_{1}$ & 220 picofarads \\
$C_{2}$ & 1760 picofarads \\
$L_{1}$ & 2.7 microhenries \\
\hline$C_{4}$ & 6 picofarads \\
$C_{5}$ & 61 picofarads \\
$L_{2}$ & 1.6 microhenries \\
\hline$C_{3}$ & 0.01 microfarads \\
\hline
\end{tabular}

Table 3: Dual-Frequency Component Values

The circuit values for the dual-frequency network are given in Table 3. All these values are approximate and may 
vary widely with different physical configurations of the network. A network analyzer is used to set up the initial values to give a resistive $50 \mathrm{ohms}$ on each input port, and the final tuning is made with a plasma by minimizing the reflected power back to each transmitter.

\section{ENHANCED PLASMA STARTING}

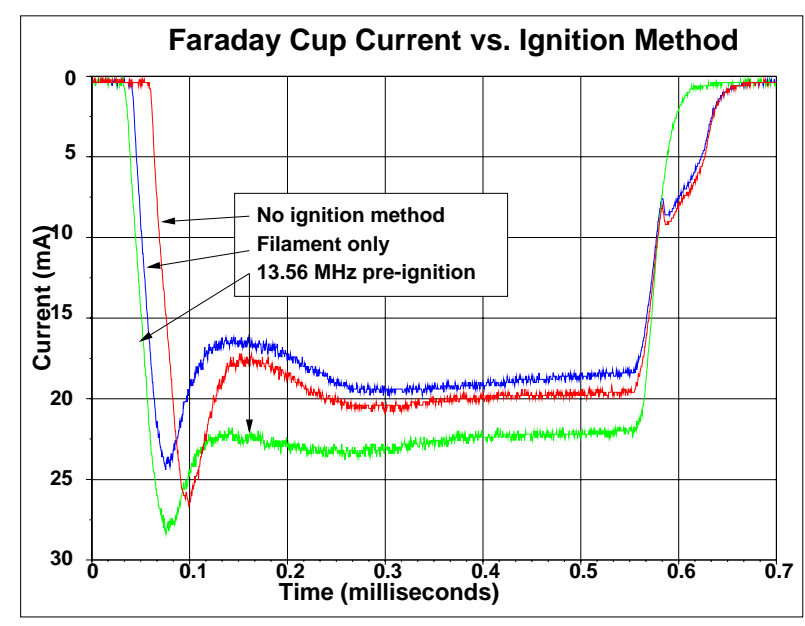

Figure 5: Source Output with Several Ignition Methods

Fig. 5 shows the leading edge of the extracted beam from a $\mathrm{H}^{-}$source using various methods of initiating the discharge. The curve with the most delay uses no auxiliary ignition method. A filament providing electrons is shown in the intermediate curve. The curve with the least delay and maximum amplitude is produced with the help of a few tens of watts of c.w. $13.56 \mathrm{MHz}$ excitation providing a steady source of pre-ignition electrons which allows rapid plasma ignition.

The dual-frequency operation provides the cleanest source operation with the fastest ignition, reducing the stress on the transmitter and matching components during the ignition period when the antenna is mismatched. In addition, it limits the peak voltages on the antenna which may cause breakdown of the insulating coating on the antenna.

\section{INCREASED POWER EFFICIENCY}

To date, a detailed comparison of extracted beam intensity has not been made, although anecdotal evidence indicates that the capacitive network is significantly more efficient at $2 \mathrm{MHz}$. Systematic data has been taken on the relative Balmer gamma line intensity of light radiated from the plasma for both networks at both $2 \mathrm{MHz}$ and the Balmer alpha intensity at $13.56 \mathrm{MHz}$.

Fig. 6 shows the relative Balmer gamma line intensity as a function of $2 \mathrm{MHz}$ r.f. power input. The upper curve for the capacitive network at $2 \mathrm{MHz}$ clearly shows a brighter emission than the lower curve for the transformer-coupled network operating into the same porcelain-coated copper antenna. Fig. 7 shows that the $13.56 \mathrm{MHz}$ branch of the

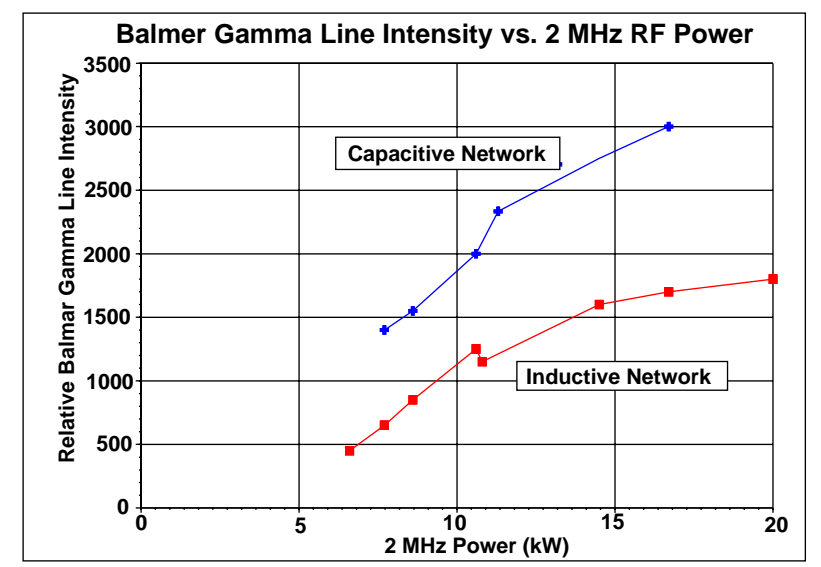

Figure 6: Emitted Light vs. $2 \mathrm{MHz}$ Power[5]

capacitive network is more efficient at low power, but less at high power than the transformer-coupled network. The normal operating $13.56 \mathrm{MHz}$ power is in the ten's of watts, the region where the capacitive network is more efficient.

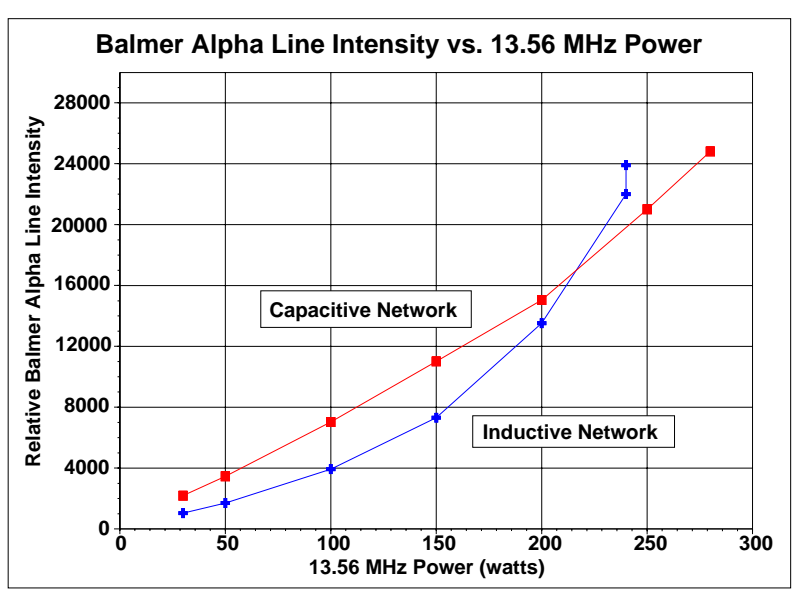

Figure 7: Emitted Light vs. $13 \mathrm{MHz}$ Power

The clear advantage at $2 \mathrm{MHz}$, where high-powered amplifiers, rated in the tens of kilowatts is apparent, where the power is costly. In addition, the capacitive network is readily adaptable to dual-frequency operation, with the two transmitters isolated from each other.

\section{ACKNOWLEDGEMENT}

Rainer Thomae provided valuable assistance in gathering the experimental data.

\section{REFERENCES}

[1] K-N Leung, RSI 71, p. 1064, (2000)

[2] www.sns.gov

[3] J. Staples, Internal Tech Note FE-PH-041, August 2000

[4] J. Staples, Internal Tech Note FE-PH-044, November 2000

[5] We used an Ocean Optics S2000 Fiber Optic Spectometer 